\title{
Effect of Valine on Propionate Metabolism in Control and Hyperglycinemic Fibroblasts and in Rat Liver
}

\author{
BETTY REVSIN, ${ }^{(36)}$ JOYCE LEBOWITZ, AND GRANT MORROW III \\ Department of Pediatrics, University of Arizona College of Medicine, Arizona Medical Center, \\ Tucson, Arizona, USA
}

\section{Summary}

Measurement of methylmalonyl-CoA mutase and propionylCoA carboxylase activities in lysates from fibroblasts derived from control, nonketotic hyperglycinemia, propionic acidemia, and both vitamin $B_{12}$-responsive and -nonresponsive variants of methylmalonic acidemia showed only one abnormality: a 59\% decrease in carboxylase activity in the nonketotic hyperglycinemic lysates $(P<0.01)$. When fibroblasts from all cell types were grown on valine-supplemented $(24 \mathrm{mM})$ media, mutase activity was generally inhibited. As for carboxylase activity, control lines were inhibited $35 \%$ as compared to controls without valine and propionic acidemia activity was undetectable. On the other hand, carboxylase activity in both methylmalonic acidemia variants was increased $40 \%$ and nonketotic hyperglycinemia carboxylase activity was increased $80 \%(P<0.01)$ when grown on valine-supplemented media. Isoleucine could not substitute for valine in producing increased carboxylase activity in these mutants.

Glycine cleavage activity in fresh rat liver homogenates (11.1 $\mu \mathrm{mol} / \mathrm{mg}$ protein $/ 90 \mathrm{~min}$ ) did not vary significantly when $24 \mathrm{mM}$ valine was added to the reaction $(9.9 \mu \mathrm{mol} / \mathrm{mg}$ protein $/ 90 \mathrm{~min})$. Therefore, the hyperglycinemia observed in both ketotic and nonketotic forms is probably not caused by a direct effect of valine on the glycine cleavage reaction.

These data suggest that the presence of increased amounts of propionic acid in serum or urine does not necessarily rule out the possibility of nonketotic hyperglycinemia due to the decreased activity of the carboxylase enzyme.

\section{Speculation}

Decreased activity of the propionyl-CoA carboxylase enzyme in nonketotic hyperglycinemia fibroblasts suggests altered propionate metabolism in this mutation. Additionally, growth of nonketotic hyperglycinemia fibroblasts on high concentrations of valine results in greatly increased carboxylase activity. This effect of valine is also evident in methylmalonic acidemia lysates although no decrease in carboxylase activity in these mutants grown under normal conditions is observed. Although the valine effect is not presently understood, it may be possible that nonketotic hyperglycinemia can be diagnosed from fibroblasts grown in tissue culture based on the combination of these two findings: (I) decreased propionyl-CoA carboxylase activity in nonketotic hyperglycinemic lysates grown under normal culture conditions and (2) increased propionyl-CoA carboxylase activity in nonketotic hyperglycinemic lysates grown on valine-supplemented media.

Hyperglycinemia is associated with a variety of diseases. Some are associated with ketosis such as methylmalonic acidemia (21), propionic acidemia (3), and isovaleric acidemia (2), whereas others exhibit no ketosis, e.g., nonketotic hyperglycinemia (4). Those hyperglycinemic states associated with ketosis appear to be diseases which result from primary enzyme defects either in the propionate pathway $(3,21)$ or in one of the catabolic pathways of branched chain amino metabolism $(2,14)$. As a result, the hyperglycinemia appears to be a secondary phenomena. In nonketotic hyperglycinemia $(\mathrm{NKH})$, it has been suggested that the primary defect causes hyperglycinemia and results from decreased activity of the glycine cleavage reaction $(26,34)$. However, recent studies have demonstrated diminished glycine cleavage activity in the ketotic forms of hyperglycinemia as well as in the nonketotic form $(25,32)$. These latter observations suggest that the decreased glycine cleavage activity found in the NKH syndrome may be a secondary phenomena possibly due to mechanisms similar to those seen in the ketotic states.

Studies from our own laboratory have demonstrated that fibroblasts derived from patients with $\mathrm{NKH}$ have a decreased ability to transport glycine across the cell membrane (29). The $\mathrm{K}_{\mathrm{m}}$ for the controls and the NKH cell lines were similar indicating that the affinity of the respective carrier protein(s) for glycine was no different in the mutant lines. However, the $V_{\max }$ was significantly lower in the NKH lines as compared to the controls, indicating that the movement of the carrier across the membrane and/or dissociation of the carrier and the glycine molecule are depressed $(24,29)$.

A report presented several years ago suggested that in acute $\mathrm{NKH}$, propionate metabolism was normal (8). In a more recently published report, the same author hypothesized that the "true nonketotic hyperglycinemic state" is one in which both propionate and branched chain amino acid metabolism are normal in vitro and in vivo (7). Furthermore, the report stated that oral loading of $\mathrm{NKH}$ patients with leucine, isoleucine, valine, methionine, and threonine had no clinical effect on the patient (7). These data are incompatible with several other reports describing coma in NKH patients after oral valine loads $(16,17$, $20)$. Our NKH patient became comatose upon oral administration of valine. Since isoleucine and leucine were without effect, the coma appeared to be valine specific (20).

The reasons for the different chemical responses to valine require further investigation in order to identify the underlying defect or defects in NKH. Indeed, the mechanism by which hyperglycinemia manifests itself as a characteristic of the ketotic hyperglycinemic diseases also remains unknown.

In contrast to the report of normal propionate metabolism in nonketotic hyperglycinemia $(7,8)$, evidence derived from studies in our laboratory have shown altered propionyl-CoA carboxylase activity in fibroblasts derived from NKH patients and from some methylmalonic acidemia (MM-emia) fibroblasts when grown on valine-supplemented media. The present manuscript presents further in vitro data concerning the activity of propio- 
nate enzymes (propionyl-CoA carboxylase and methylmalonylCoA mutase), as well as the effect of the branched chain amino acid, valine, on these activities in control and mutant fibroblasts.

\section{MATERIALS AND METHODS}

\section{FIBROBLASTS}

Fibroblasts from control, NKH, propionic acidemia (PA), and MM-emia explants were grown on Eagle's minimum essential media supplemented with $10-12 \%$ fetal calf serum, 100 units $/ \mathrm{ml}$ penicillin, and $100 \mu \mathrm{g} / \mathrm{ml}$ streptomycin. Media was changed every third day. All cells were below passage 20 .

For the enzyme assays, fibroblasts were routinely grown to confluence in disposable roller bottles (Bellco), harvested with $0.125 \%$ trypsin-Versene, and centrifuged at $500 \times \mathrm{g}$ for $5 \mathrm{~min}$. The cells were washed once with $12 \mathrm{ml}$ saline/roller bottle of cells and centrifuged again at $500 \times g$ for $5 \mathrm{~min}$. The washed fibroblasts were resuspended in water $(0.1 \mathrm{ml}$ cells $/ 0.15 \mathrm{ml}$ water) and lysed by freeze-thawing five times in a dry iceacetone bath. The resulting lysate was centrifuged at $2000 \times g$ for $10 \mathrm{~min}$. The supernatant was used in all following enzyme assays.

Methylmalonyl-CoA carbonylmutase (mutase) was assayed as described previously (22), and propionyl-CoA carboxylase activity (carboxylase) was measured according to the method of Giorgio and Whitaker (13) with some modifications (22).

When cells were grown on increased concentrations of valine or isoleucine, the roller bottles were seeded in the usual manner and allowed to grow for 3 days. At that time, the media containing the increased concentration of valine were introduced to the cells. Growth of the cells was allowed to continue until confluence, usually 4 more days.

\section{LIVER HOMOGENATES}

Fresh rat liver was homogenized by hand in all glass vessels in 2 volumes of $0.25 \mathrm{M}$ sucrose at $4^{\circ}$. The homogenate was centrifuged for $15 \mathrm{~min}$ at $2000 \times \mathrm{g}$ at $4^{\circ}$. The resultant supernatant, which contained only trace amounts of glycine oxidase activity, was discarded. The pellet or "particulate fraction" was resus-

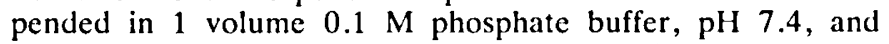
corresponds to the "particulate" fraction derived from avian liver as described by Richert et al. (30). The resuspended particulate fraction was used to measure the release of ${ }^{14} \mathrm{CO}_{2}$ from [1$\left.{ }^{14} \mathrm{C}\right]$ glycine according to the method of Sato et al. (31).

\section{RESULTS}

\section{PROPIONYL COA CARBOXYLASE ACTIVITY (TABLE 1)}

Propionyl-CoA carboxylase (carboxylase) activity was assayed in cell-free extracts of fibroblasts cultured from control, PA, $\mathrm{NKH}$, and both variants of MM-emia. Patients with MM-emia generally fall into two categories. One group cannot synthesize adenosylcobalamin, the coenzyme for methylmalonyl-CoA mutase (mutase), and will respond to vitamin $\mathrm{B}_{12}$ therapy in vivo and in vitro (19). The second group reflects defective synthesis of the mutase apoenzyme and consequently cannot respond to vitamin $B_{12}$ therapy (19).

The carboxylase activity of the control and of both the vitamin $B_{12}$ responder and nonresponder variants of $\mathrm{MM}$-emia was similar (Table 1). However, the carboxylase activity was decreased in the NKH lines when compared to the controls. The values obtained with these cell lines characteristically and repeatedly fell into the extreme low end of the normal range. Statistical comparison of the control and the NKH lines using the $t$-test showed the decreased carboxylase activity in the NKH cells was significant at the 0.01 level $(P<0.01)$. With the PA cell extracts only a trace of activity was measurable, as was expected since the carboxylase enzyme had been identified as the genetic defect in the fibroblasts from these patients.

\section{METHYLMALONYL-COA MUTASE ACTIVITY (TABLE 2)}

In our MM-emia lines incorporation of ${ }^{14} \mathrm{CO}_{2}$ into methylmalonate from $\mathrm{NaH}{ }^{14} \mathrm{CO}_{3}$ is an expression of propionyl-CoA carboxylase and methylmalonyl-CoA racemase activities due to the fact that the mutase enzyme is defective in the MM-emia lines. Thus the ${ }^{14} \mathrm{C}$ accumulates as methylmalonate. However, in the control and $\mathrm{NKH}$ fibroblasts the majority of the ${ }^{14} \mathrm{C}$ label accumulates as succinyl-CoA since all of the propionate pathway enzymes are theoretically intact. Little metabolism of succinylCoA occurs in these cultured cells because of greatly diminished succinic dehydrogenase activity (35). Nonetheless, small amounts of label can be recovered from methylmalonyl-CoA, tricarboxylic acid cycle intermediates, and as bicarbonate. It was important, therefore, to measure methylmalonyl-CoA mutase activity in these cell lines to determine whether the decreased carboxylase activity of the NKH cells was indeed due to decreased activity at that step or whether the decreased activity was a reflection of impaired mutase function.

Table 2 shows that the mutase activity in the control, NKH, $\mathrm{PA}$, and vitamin $\mathrm{B}_{12}$-responder lysates is quite similar. The nonresponder mutase activity is almost nil since it is the apoenzyme that is defective in this mutation (19). As a result of the similar mutase activities in these control and mutant cell lines, the depressed carboxylase activity observed in the NKH lines is probably due to an effect at that step in propionate metabolism rather than at the mutase level.

\section{EFFECT OF VALINE ON CARBOXYLASE AND MUTASE ACTIVITIES (TABLES 1 AND 2)}

Since valine is toxic to both NKH and MM-emia patients, it was of interest to determine the effect of this amino acid on carboxylase and mutase activities. Fibroblasts were grown on media supplemented with $24 \mathrm{mM}$ valine. Minimal essential medium contains $0.80 \mathrm{mM}$ valine which, when added to the valine present in fetal calf serum, brings the total valine concentration to approximately $1 \mathrm{mM}$. Thus, the valine-supplemented media was approximately $25 \mathrm{mM}$.

Table 1 (carboxylase) and Table 2 (mutase) show that growth of control fibroblasts on valine-supplemented media caused a slight inhibition of carboxylase activity $(35 \%)$ as well as mutase activity $(37 \%)$. In contrast, all the $\mathrm{NKH}$ lines exhibited increased carboxylase activity $(80 \%)$ when grown on excess valine as compared to NKH cells grown in regular media. Statistical analysis using the $t$-test showed that valine-stimulated carboxylase activity was significant at the 0.01 level $(P<0.01)$. This increased carboxylase activity brought the activity of the NKH lysates to the midrange of the controls grown under normal conditions. Also, the carboxylase activity of the MM-emia fibroblasts (both responder and nonresponder variants) was stimulated by approximately $40 \%$. Although the $n$ value of this group is small, the increased activity of the MM-emia mutants was observed every time. Valine failed to induce any carboxylase activity in the PA lysates.

Mutase activity of all the cell lines when grown under conditions of valine supplementation was slightly inhibited (Table 2). The inhibition appeared to be nonspecific since all the reactions from all the cell lines were inhibited to more or less the same degree.

\section{EFFECT OF ISOLEUCINE ON CARBOXYLASE AND MUTASE ACTIVITIES (TABLE 3)}

Since isoleucine feeds into the propionate pathway as does valine, it was of interest to determine whether fibroblasts grown on excess isoleucine also affected carboxylase or mutase activities. Control, MM-emia (both variants), and NKH fibroblasts were grown on $24 \mathrm{mM}$ isoleucine which, when added to the isoleucine already present in the growth media, gave a final isoleucine concentration of approximately $25 \mathrm{mM}$. None of these mutants showed increased carboxylase activity when grown in the presence of excess isoleucine and the same was true 
Table 1. Propionyl-CoA carboxylase activity in cell-free extracts obtained from cells grown under normal culture conditions and supplemented with valine

\begin{tabular}{|c|c|c|c|c|c|}
\hline Media & Controls & $\mathrm{NKH}$ & \multicolumn{2}{|c|}{ Methylmalonic acidemia } & $\mathrm{PA}$ \\
\hline No. lines & 6 & 3 & 3 & 3 & 3 \\
\hline Activity, mean & 1.27 & 0.52 & 1.15 & 0.88 & 0.05 \\
\hline Activity, range & $0.55-3.1$ & $0.30-0.74$ & $0.43-2.5$ & $0.48-1.3$ & $0.02-0.09$ \\
\hline No. lines & 3 & 3 & 1 & 1 & 3 \\
\hline Activity, mean & 0.83 & 0.94 & 1.60 & 1.27 & 0 \\
\hline Activity, range & $0.66-0.91$ & $0.61-1.6$ & $1.45-1.72$ & $1.20-1.29$ & \\
\hline$n$ & 3 & 9 & 3 & 3 & 3 \\
\hline
\end{tabular}

${ }^{1}$ Activity expressed as nanomoles of ${ }^{14} \mathrm{CO}_{2}$ incorporated per $\mathrm{mg}$ protein per min. The reaction mixture contained $81 \mathrm{mM}$ tris, $\mathrm{pH} 8.5 ; 12.5 \mu \mathrm{mol}$ $\mathrm{NaH}^{14} \mathrm{CO}_{3}$ (specific activity $0.16 \mu \mathrm{Ci} / \mu \mathrm{mol}$ ); $2.7 \mathrm{mM} \mathrm{ATP} ; 3.3 \mathrm{mM}$ reduced glutathione; $6.7 \mathrm{mM} \mathrm{MgCl} ; 10 \mu \mathrm{g} \mathrm{Biotin} ; 100 \mathrm{mM} \mathrm{KCl} ; 1.35 \mathrm{mM}$ propionyl-CoA, and $250-500 \mu \mathrm{g}$ lysate protein. The reaction mixture had a total volume of $350 \mu l$. NKH: nonketotic hyperglycinemia; PA: propionic acidemia.

${ }^{2}$ Number of experiments.

Table 2. Methylmalonyl-CoA mutase activity ${ }^{1}$ in cell-free extracts obtained from cells grown under normal culture conditions and supplemented with valine

\begin{tabular}{|c|c|c|c|c|c|}
\hline Media & Controls & $\mathrm{NKH}$ & \multicolumn{2}{|c|}{ Methylmalonic acidemia } & PA \\
\hline No. lines & 4 & 2 & 2 & 3 & 3 \\
\hline Activity, mean & 0.74 & 0.63 & 0.58 & 0.06 & 0.84 \\
\hline Activity, range & $0.28-1.73$ & $0.28-0.84$ & $0.22-1.2$ & $0-0.27$ & $0.19-2.25$ \\
\hline No. lines & 4 & 2 & 2 & 2 & 3 \\
\hline Activity, mean & 0.46 & 0.48 & 0.32 & 0.023 & 0.64 \\
\hline Activity, range & $0.11-0.95$ & $0.11-0.78$ & $0.07-0.76$ & $0-0.046$ & $0.06-1.38$ \\
\hline$n$ & 5 & 4 & 5 & 2 & 9 \\
\hline
\end{tabular}

${ }^{1}$ Activity expressed as nanomoles of $\left[{ }^{14} \mathrm{C}\right]$ succinate formed/mg protein/min. The reaction mixture contained $10.1 \mathrm{nmol}\left[2-\mathrm{methyl}-{ }^{14} \mathrm{C}\right] \mathrm{malonyl}-$

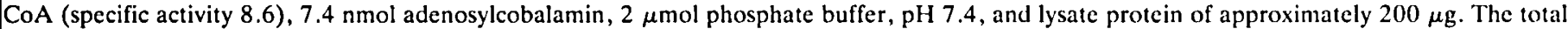
reaction volume was $100 \mu \mathrm{l}$. NKH: nonketotic hyperglycemia; PA: propionic acidemia.

${ }^{2}$ Number of experiments.

for mutase activity (Table 3 ). If anything, there was generally a slight inhibition of activities, but it was negligible. Thus, it appears that the stimulation of carboxylase activity in the NKH and MM-emia mutants is specific to valine.

\section{GLYCINE OXIDATION (TABLE 4)}

The reasons for the glycine elevations in the disease states studied here remain unknown. However, the effect of valine in these hyperglycinemic diseases suggests that valine or one of its catabolic products may inhibit glycine oxidation, thus leading to hyperglycinemia. Attempts to measure glycine oxidation in cultured skin fibroblasts have not been successful in this laboratory, although it has been reported to occur by one investigator (14). Because of these facts, we measured glycine oxidation utilizing fresh rat liver homogenates. The effect of valine on the glycine cleavage reaction in rat liver would be equivalent to results obtained from a control subject (Table 4).

When valine was present in the reaction mixture to give a final concentration of $24 \mathrm{mM}$, a small inhibition in the production of ${ }^{14} \mathrm{CO}_{2}$ from $\left[1-{ }^{14} \mathrm{C}\right]$ glycine was observed. The activities obtained for the glycine cleavage reaction with these liver homogenates were somewhat variable over a fairly large range. However, in each trial the activity of the valine-supplemented reaction was always in the same direction, a slight decrease in activity.

\section{DISCUSSION}

A great deal of confusing data have been reported regarding the disease entity nonketotic hyperglycinemia, particularly the effects of valine on patients with this disease. We therefore examined the activities of several enzymes in the propionate pathway and the effects of valine on these enzymes in lysates of fibroblasts derived from NKH patients and ketotic hyperglycinemic patients as well.

Measurement of methylmalonyl-CoA mutase and propionylCoA carboxylase activities in these mutant lines showed only one abnormality, decreased carboxylase activity in the NKH lysates significant at the 0.01 level. Although propionyl-CoA carboxylase activity is significantly decreased in the nonketotic hyperglycinemic lysates, there is considerable residual activity (40\% of control). Consequently, whether this decreased activity has relevance in vivo remains to be demonstrated. There has been one report by Farriaux et al. (12) demonstrating increased propionate excretion in their NKH patient. Measurement of carboxylase and glycine cleavage activities in a liver biopsy from this same patient showed normal carboxylase activity and a virtual absence of glycine cleavage activity. However, because of the briefness of the above report (12), conditions for measurement of these enzymes activities are not well described.

When grown on valine-supplemented media, mutase activity 
Table 3. Propionyl-CoA carboxylase and methylmalonyl-CoA mutase activities ${ }^{1}$ in cell-free extracts from cells grown under normal culture conditions and supplemented with isoleucine ${ }^{2}$

\begin{tabular}{|c|c|c|c|c|}
\hline \multirow[b]{2}{*}{ Cell lines } & \multicolumn{2}{|c|}{$\begin{array}{c}\text { Carboxylase activity in } \\
\text { media }\end{array}$} & \multicolumn{2}{|c|}{$\begin{array}{l}\text { Mutase activity } \\
\text { in media }\end{array}$} \\
\hline & Regular & Isoleucine & Regular & Isoleucine \\
\hline \multicolumn{5}{|l|}{ Controls (2 lines) } \\
\hline Activity, mean & 0.85 & 0.77 & 0.62 & 0.71 \\
\hline Activity, range & $0.78-0.92$ & $0.70-0.83$ & $0.52-0.72$ & $0.50-0.92$ \\
\hline$n^{3}$ & 2 & 2 & 2 & 2 \\
\hline \multicolumn{5}{|l|}{$\begin{array}{l}\text { Methylmalonic } \\
\text { acidemia }\end{array}$} \\
\hline Activity, mean & 0.87 & 0.92 & 0.51 & 0.49 \\
\hline Activity, range & $0.83-0.90$ & $0.80-1.03$ & $0.21-0.81$ & $0.19-0.79$ \\
\hline$n$ & 2 & 2 & 2 & 2 \\
\hline \multicolumn{5}{|l|}{$\begin{array}{c}\text { B }_{12} \text { unresponsive } \\
\text { (2 lines })\end{array}$} \\
\hline Activity, mean & 0.70 & 0.64 & 0.086 & 0.084 \\
\hline Activity, range & $0.54-0.85$ & $0.44-0.84$ & & \\
\hline$n$ & 2 & 2 & 1 & 1 \\
\hline \multicolumn{5}{|l|}{ NKH (2 lines) } \\
\hline Activity, mean & 0.61 & 0.52 & 0.66 & 0.68 \\
\hline Activity, range & $0.60-0.62$ & $0.50-0.54$ & $0.63-0.69$ & $0.61-0.75$ \\
\hline$n$ & 2 & 2 & 2 & 2 \\
\hline
\end{tabular}

Table 4. Effect of valine and isoleucine on glycine oxidation in rat liver homogenates ${ }^{1}$

\begin{tabular}{|c|c|}
\hline & $\begin{array}{c}\mathrm{nmol}{ }^{14} \mathrm{CO}_{2} / \\
\mathrm{mg} \text { protein/ } \\
90 \mathrm{~min}\end{array}$ \\
\hline \multicolumn{2}{|l|}{ Liver homogenate } \\
\hline Activity, mean & 11.1 \\
\hline Activity, range & $2.9-31.4$ \\
\hline$n^{2}$ & 6 \\
\hline \multicolumn{2}{|c|}{ Liver homogenate $+24 \mu \mathrm{mol}$ valine } \\
\hline Activity, mean & 9.9 \\
\hline Activity, range & $2.7-24.1$ \\
\hline$n$ & 6 \\
\hline \multicolumn{2}{|c|}{$\begin{array}{l}{ }^{1} \text { The reaction mixture contained } 10 \mu \mathrm{mol}\left[1-{ }^{14} \mathrm{C}\right] \text { glycine (specific } \\
\text { activity } 0.1 \mu \mathrm{Ci} / \mu \mathrm{mol}), 1 \mu \text { mol tetrahydrofolate; } 1.5 \mu \mathrm{mol} \text { pyridoxa } \\
\text { phosphate, } 1 \mu \mathrm{mol} \text { nicatinamide adenine dinucleotide; } 10 \mu \mathrm{mol} \text { reduced } \\
\text { glutathione; } 150 \mu \mathrm{mol} \text { phosphate buffer, } \mathrm{pH} 7.4 \text {, and } 2-5 \mathrm{mg} \text { particulate } \\
\text { liver protein. The final reaction volume } 1.0 \mathrm{ml} \text {. The reaction was run for } \\
90 \text { min at } 37^{\circ} \text {. } \\
{ }^{2} \text { Number of experiments. }\end{array}$} \\
\hline
\end{tabular}

in all cell lines tested was generally inhibited. As for carboxylase activity, control lines showed a decrease in activity whereas NKH lysates and both MM-emia variants exhibited a large increase in carboxylase activity when exposed to valine. The MM-emia lines averaged a $40 \%$ increase in activity and the NKH lysates increased their carboxylase activity $80 \%(P<$ $0.01)$. There seemed to be both a specific and a nonspecific aspect of the valine effect. The specific aspect was that isoleucine could not induce carboxylase activity as did valine. The nonspecific aspect was that the valine-stimulated carboxylase activity occurred in both NKH and MM-emia lysates. This does not help clarify the in vivo effect of valine in NKH patients.

Increased carboxylase activity in the NKH and MM-emia lysates when grown on valine-supplemented media may repre- sent activity of the carboxylase enzyme in the reverse direction, toward production of propionyl-CoA. Indeed, Kaziro et al. (15) have demonstrated that the carboxylase enzyme is readily reversible, with the equilibrium being only slightly in favor of propionyl-CoA carboxylation. Additionally, Tanaka et al. (33) demonstrated by nuclear magnetic resonance spectroscopy that methylmalonic acid semialdehyde, an intermediate of valine catabolism, is decarboxylated to propionate and then converted to methylmalonyl-CoA via the carboxylase enzyme. Therefore, valine appears to induce propionyl-CoA carboxylase activity. Several possible fates for excess propionate produced in vivo have been suggested. One report has indicated that in a PA patient, large amounts of methylcitrate were excreted in the urine from the condensation of propionyl-CoA and oxaloacetate (5). Propionyl-CoA can also act as the primer for odd chain fatty acid synthesis (9), and may thus be the fate of the propionylCoA being produced under conditions of excess valine.

Baumgartner et al. $(7,8)$ have suggested that in the $\mathrm{NKH}$ patient, the enzymes of the propionate pathway are normal. These studies were performed using the substrates propionyl$\mathrm{CoA}$ and $\mathrm{NaH}^{14} \mathrm{CO}_{3}$ and measuring ${ }^{14} \mathrm{C}$ label incorporated into methylmalonyl-CoA, succinyl-CoA, and other organic acids. Most of the label was recovered as succinate which is formed by the third enzyme in the propionate pathway. In any series of enzymatic reactions, the rate of formation of the end product is only as rapid as the rate-limiting enzyme in the series. Data reported above indicate that the carboxylase enzyme is not the rate-limiting step in the series. Under normal circumstances then, the label recovered in succinyl-CoA would not be a reflection of the activity of the carboxylase enzyme but the enzyme with the lowest $\mathrm{V}_{\max }$. Consequently, defective or decreased activity of any single enzyme in a series can be overlooked unless the particular enzyme being studied possesses the rate-limiting $\mathrm{V}_{\max }$ of the series. Additionally, it was not possible for us to demonstrate propionyl-CoA carboxylase activity in livers stored in the frozen state after periods exceeding 1-2 months (22), as did Baumgartner et al. (7). The carboxylase instability we noted is consistent with the findings of Giorgio and Whitaker (13).

Presently, the basic defect of $\mathrm{NKH}$ has not been definitely established although two abnormalities of glycine metabolism have been demonstrated in these patients, i.e., decreased ability to transport glycine across the cell membrane (29) and diminished glycine cleavage reaction $(4,28,32)$. The diminished glycine cleavage noted in $\mathrm{NKH}$ patients who have had [1$\left.{ }^{14} \mathrm{C}\right]$ glycine and/or $\left[2-{ }^{14} \mathrm{C}\right]$ glycine administered to them may be a reflection of a decreased ability to transport glycine across the cell membrane. However, liver biopsy homogenates $(12,34)$ from these patients generally demonstrate low glycine cleavage activity. This decreased liver activity could very well be nonspecific since it is also observed in hyperglycinemic states characterized by ketosis $(25,32)$.

Perry et al. (28) measured glycine levels and glycine cleavage activity in cerebrospinal fluid and in brain from patients with hyperglycinemia of unspecified type and nonketotic hyperglycinemia. In the NKH patients, both spinal fluid and brain content of glycine was greatly elevated and glycine cleavage virtually absent, whereas for the unspecified hyperglycinemics, brain glycine content and glycine cleavage activity were normal. These data are of great interest. However, it is also necessary to measure this reaction in brain tissue in the ketotic hyperglycinemic diseases. It is interesting to postulate that if glycine is a natural inhibitory transmitter in the central nervous system (6), the severe neurologic systems associated with NKH may be due to glycine accumulation and that these effects are exacerbated by valine.

With regard to the valine effects in NKH, de Groot et al. (10) and Krieger and Hart (16) demonstrated that valine was catabolized at a slower rate in NKH patients than in control subjects. de Groot $e t$ al. (10) showed that glycine competitively inhibited the uptake of valine in rat liver slices and thus postulated that the decrease in valine catabolism in NKH may be due to high plasma 
glycine levels. This may be true; however, until further proof is offered this is a premature conclusion. In many tissues in which neutral amino acid transport has been studied, it has been demonstrated that both glycine and valine are capable of being transported by the same transport carriers $(1,11,27,29)$. Thus, glycine inhibition of valine transport is a result of competition for the same transport carriers and this competition may be competitive in nature. Many other amino acids also compete for the same carrier sites as valine. Therefore, in order to make a statement about glycine inhibition of valine transport in $\mathrm{NKH}$ patients as being causative, it would be necessary to make transport measurements in liver slices in a media simulating plasma amino acid composition of a NKH patient.

Finally, NKH is considered a homogeneous entity. However, if the main defect is decreased glycine cleavage activity, heterogeneity is to be expected since this overall reaction requires the presence of four.different proteins (18). The seemingly contradictory clinical responses to valine remain unexplained and may, in fact, represent different NKH variants. How the glycine transport defect fits into the overall picture is not quite clear at this time.

\section{CONCLUSION}

1. Methylmalonyl-CoA mutase activity in cell-free extracts prepared from fibroblasts was similar in control, $\mathrm{PA}, \mathrm{NKH}$, and vitamin $\mathrm{B}_{12}$-responsive MM-emia.

2. In $\mathrm{NKH}$ lysates, propionyl-CoA carboxylase activity was significantly $(P<0.01)$ diminished when compared to control and MM-emia cell lines.

3. Fibroblasts grown on valine-supplemented media generally exhibited decreased mutase activity.

4. Increased valine concentrations in the media had little to no effect on carboxylase activity in control lysates. Lysates from NKH exhibited significant increases $(P<0.01)$ in carboxylase activity. MM-emia variants also exhibited increased carboxylase activity.

5. Substitution of isoleucine for valine in the growth media did not induce carboxylase activity in the mutant cell lines.

6. Valine had no effect on glycine oxidation in rat liver homogenates, suggesting that the hyperglycinemia seen in both the ketotic and the nonketotic diseases is not due to a direct effect of valine on the glycine cleavage reaction.

\section{REFERENCES AND NOTES}

1. Adamson, L. F., and Ingbar, S. H.: Further studies of amino acid transport by embryonic chick bone. J. Biol. Chem., 242: 2646 (1967)

2. Ando, T., Klingberg, W. G., Ward, A. N., Rasmussen, K., and Nyhan, W. L.: Isovaleric acidemia presenting with altered metabolism of glycine. Pediat. Res., 5: 478 (1971).

3. Ando, T., Nyhan, W. L., Connar, J. D., Rasmussen, K., Donnell, G. N. Barnes, N. D., Cottom, D., and Hull, D.: The oxidation of glycine and propionic acid in propionic acidemia with ketotic hyperglycinemia. Pediat. Res., 6: 576 (1972).

4. Ando, T., Nyhan, W. L., Gerritsen, T., Gong, L., Heiner, D. C., and Bray, P. F.: Metabolism of glycine in the nonketotic form of hyperglycinemia. Pediat. Res., 2: 254 (1968).

5. Ando, T., Rasmussen, K., Wright, J. M., and Nyhan, W. L.: Isolation and identification of methylcitrate, a major metabolite product of propionate in patients with propionic acidemia. J. Biol. Chem., 247: 2200 (1972).

6. Arregui, A., Logan, W. J., Bennett, J. P., and Snyder, S. H.: Specific glycineaccumulating synaptosomes in the spinal cord of rats. Proc. Natl. Acad. Sci. U. S. A., 69: 3485 (1972).

7. Baumgartner, E. R., Bachmann, C., Brechbuhler, T., and Wick, H.: Acute neonatal nonketotic hyperglycinemia: Normal propionate and methylmalonate metabolism. Pediat. Res., 9: 559 (1975).

8. Baumgartner, E. R., and Wick, H.: Normal propionate metabolism in "nonketotic hyperglycinemia." N. Engl. J. Med., 286: 784 (1972).

9. Bressler, R., and Wakil, S. J.: Studies on the mechanism of fatty acid synthesis
$\mathrm{XI}$. The product of the reaction and the role of sulfhydryl groups in the synthesis of fatty acids. J. Biol. Chem., 237: 1441 (1962).

10. Groot, C. J., van den Berg, H., and Hommes, F. A.: Studies on the valine sensitivity in nonketotic hyperglycinemia. Helv. Paediat. Acta, 30: 247 (1975).

11. Eavenson, E., and Christensen, H. N.: Transport systems for neutral amino acids in the pigeon erythrocyte. J. Biol. Chem., 242: 5386 (1967).

12. Farriaux, J. P., Morel, P., and Hommes, F. A.: Nonketotic hyperglycinemia with increased propionic acid excretion and hyperammonemia. $\mathrm{N}$. Engl. J. Med., 292: 558 (1975).

13. Giorgio, A. J., and Whitaker, T. R.: Some properties of propionyl CoA carboxylase partially purified from human liver. Biochem. Med., 7: 473 (1973).

14. Hillman, R. E., Sowers, L. H., and Cohen, J. L.: Inhibition of glycine oxidation in cultured fibroblasts by isoleucine. Pediat. Res., 7: 945 (1973).

15. Kaziro, Y., Grossman, A., and Ochoa, A.: Metabolism of propionic acid in animal tissues. J. Biol. Chem., 240: 64 (1965).

16. Krieger, I., and Hart, Z. H.: Valine-sensitive nonketotic hyperglycinemia. J. Pediat., 85: 43 (1974).

17. Levy, H. L., Nishimura, R. N., Erickson, A. M., and Janowska, S. E. Hyperglycinemia: In vivo comparison of nonketotic and ketotic (propionic acidemia) forms. II. Valine response in nonketotic hyperglycinemia. Pediat. Res., 6: 395/135 (1972).

18. Matokawa, Y., and Kikuchi, G.: Glycine metabolism in rat liver mitochondria. Arch. Biochem. Biophys., 146: 461 (1971).

19. Morrow, G., III: In: W. L. Nyhan: Methylmalonic Acidemia in Heritable Disorders of Amino Acid Metabolism, pp. 61-80 (John Wiley \& Sons, New York, 1974)

20. Morrow, G., III: Personal observations

21. Morrow, G., Barness, L. A., Auerbach, U. H., DiGeorge, A. M., Anto, T., and Nyhan, W. L.: Observations on the co-existence of methylmalonic acidemia and glycinemia. J. Pediat., 74: 680 (1969).

22. Morrow, G., Lebowitz, J., Revsin, B., and Giles, H.: Propionate metabolism in fetal livers of 15 to 19 weeks' gestation. Amer. J. Obstet. Gynecol., 121 269 (1975).

23. Morrow, G., III, Mahoney, M. J., Mathews, C., and Lebowitz, J.: Studies of methylmalonyl coenzyme A carbonylmutase activity in methylmalonic acidemia. I. Correlation of clinical, hepatic, and fibroblast data. Pediat. Res., 9: 641 (1975).

24. Neame, K. D., and Richards, T. G.: Elementary Kinetics of Membranc Carrier Transport (John Wiley \& Sons, New York, 1972).

25. Nishimura, G., Tada, K., and Arakawa, T.: Coexistence of defective activity in glycine-cleavage reaction and propionyl CoA carboxylase deficiency in the liver of a hyperglycinemic child. Tohoku J. Exp. Med., 113: 267 (1974).

26. Nyhan, W. L.: Nonketotic hyperglycinemia. In: The Metabolic Basis of Inherited Disease J. B. Stanbury, J. B. Wyngaarden, and D. S. Fredrickson: (McGraw-Hill Book Company, New York, 1971).

27. Oxender, D. L., and Christensen, H. N.: Distinct mediating systems for the transport of neutral amino acids by the Ehrlich cell. J. Biol. Chem., 238: $3686(1963)$

28. Perry, T. L., Urquhart, N., MacLean, J., Evans, M. E., Hansen, S., Davidson, A. G. F., Applegarth, D. A., MacLeod, P. J., and Lock, J. E. Nonketotic hyperglycinemia: Glycine accumulation due to absence of glycine cleavage in brain. N. Engl. J. Med., 292: 1269 (1975).

29. Revsin, B., and Morrow, G., III: Glycine transport in normal and nonketotic hyperglycinemic human diploid fibroblasts. Exp. Cell Res., 100: 95 (1976).

30. Richert, D. A., Amberg, R., and Wilson, M.: Metabolism of glycine by avian liver. J. Biol. Chem., 237: 99 (1962)

31. Sato, T., Kochi, H., Sato, N., and Kikuchi, G.: Glycine metabolism in rat liver mitochondria. J. Biochem., 65: 77 (1969).

32. Tada, K., Carbeel, L. M., Eeckels, R., and Eggermont, E.: A block in glycine cleavage as a common mechanism in ketotic and nonketotic hyperglycinemia. Pediat. Res., 8: 721 (1974).

33. Tanaka, K., Armitage, I. M., Ramsdell, H. S., Hsia, Y. E., Lipsky, S., and Rosenberg, L. E.: $\left[{ }^{13} \mathrm{C}\right]$ Valine metabolism in methylmalonicacidemia using nuclear magnetic resonance: Propionate as an obligate intermediate. Proc. Natl. Acad. Sci. U. S. A., 72: 3692 (1975)

34. Trijbels, J. M. F., Monnens, L. A. H., Van der Zee, S. P. M., Vrenken, J. A. T., Sengers, R. C. A., and Schretlen, E. D. A. M.: A patient with nonketotic hyperglycinemia: Biochemical findings and therapeutic approaches. Pediat. Res., 8: 598 (1974).

35. Turner, G. S.: Succinic dehydrogenase in short-term cultures of normal cells. Nature, 193: 164 (1962)

36. This research was supported by grants from the National Foundation-March of Dimes and Grant HD 06575 from the National Institutes of Health.

37. Requests for reprints should be addressed to: B. K. Revsin, Ph.D., Department of Pediatrics, University of Arizona College of Medicine, Health Sciences Center, Tucson, Ariz. 85724 (USA)

38. Received for publication July $5,1976$.

39. Accepted for publication October $27,1976$. 